\title{
Metodologias participativas e desenvolvimento local: a experiência do Projeto Dom Hélder Câmara no assentamento Moacir Lucena*
}

\author{
Participatory methodologies and local development: the experience of Dom \\ Helder Camara Project in Moacir settlement Lucena \\ Méthodologies participatives et développement local: l'expérience du Projet \\ Dom Helder Camara sur règlement Moacir Lucena
}

\section{Metodologías participativas y desarrollo local: la experiencia del Proyecto Dom Helder} Camara en asentamiento Moacir Lucena

\author{
Josiani Alves de Morais** \\ Angelo Brás Fernandes Callou** \\ Recebido em 06/07/2016; revisado e aprovado em 01/02/2017; aceito em 01/02/2017 \\ DOI: http:/ / dx.doi.org/10.20435/1984-042X-2017-v.18-n.1(13)
}

\begin{abstract}
Resumo: O objetivo deste artigo é analisar as metodologias participativas do Projeto Dom Hélder Câmara (PDHC), no assentamento Moacir Lucena, no Rio Grande do Norte. Os resultados revelaram que as metodologias participativas utilizadas pelo PDHC possibilitaram um avanço na participação dos agricultores nos aspectos sociais e econômicos do assentamento, com reflexos positivos nos processos de desenvolvimento local da comunidade em Moacir Lucena.

Palavras-chave: PDHC; metodologias participativas; desenvolvimento local; extensão rural.

Abstract: The aim of this work is to analyze the participative methods of Projeto Dom Hélder Câmara (PDHC) in Lucena Moacir Rio Grande do Norte. The results presented by the analysis showed that the participatory methodologies used by PDHC enabled an improvement in the participation of farmers in social and economic aspects of the settlement, with a positive impact on the local community development processes in Moacir Lucena.
\end{abstract}

Key words: PDHC; participatory methodologies; local development; rural extension.

Résumé: Le but de cet article est d'analyser les méthodologies participatives de Projeto Dom Hélder Câmara (PDHC), dans le règlement Moacir Lucena dans la Rio Grande do Norte, Nord-Est du Brésil. Les résultats ont souligné les analyses présentées, révélant que les méthodologies participatives utilisées par PDHC ont permis une amélioration de la participation des agriculteurs dans les aspects sociaux et économiques de l'établissement, avec un impact positif sur les processus de développement des communautés locales dans Moacir Lucena.

Mots-clés: PDHC; méthodologies participatives; développement local; l'extension.

Resumen: El objetivo de este artículo es analizar las metodologías participativas del Projeto Dom Hélder Câmara (PDHC) en el asentamiento de Moacir Lucena en Rio Grande do Norte. Los resultados indicaron que los análisis presentados mostraron que las metodologías participativas utilizadas por PDHC permitió una mejora de la participación de los agricultores en los aspectos sociales y económicos del asentamiento, con un impacto positivo en los procesos de desarrollo de la comunidad local en Moacir Lucena.

Palabras clave: PDHC; metodologías participativas; desarrollo local; extensión rural.

\section{INTRODUÇÃO}

O objetivo deste artigo é analisar as metodologias participativas do Projeto Dom Helder Câmara no assentamento
Moacir Lucena, no município de Apodi, Rio Grande do Norte. O que se pretende é analisar, especificamente, as contribuições dessas metodologias na perspectiva do desenvolvimento local, a partir das

\footnotetext{
* Os resultados apresentados neste artigo integram a pesquisa para título de mestre que teve apoio financeiro do CNPq.

** Universidade Federal Rural de Pernambuco (UFRPE), Recife, Pernambuco, Brasil.
} 
atividades desenvolvidas no assentamento.

O Projeto Dom Hélder Câmara (PDHC) foi iniciado em 2002. Está vinculado ao Ministério do Desenvolvimento Agrário, por meio da Secretaria de Desenvolvimento Territorial (SDT), e ao Fundo Internacional para o Desenvolvimento da Agricultura (Fida). A estrutura de organização se dá por meio da Unidade de Gestão Participativa (UGP), sendo a sede localizada na cidade do Recife, PE, onde ficam os técnicos e gestores. O Projeto Dom Hélder Câmara faz parte do plano de desenvolvimento rural criado pelo Governo federal para atender as famílias do campo, na perspectiva de aumentar a produção, rompendo com as deficiências crônicas de pobreza, sendo um relevante indicador para o fortalecimento da agricultura familiar, através de seus saberes e fazeres. Por meio da assessoria técnica permanente, propõe desenvolver metodologias participativas de geração de conhecimento, aumentando as capacidades e oportunidades das pessoas (ARAÚJO; JALFIM; SIDERSKY, 2010).

Dessa maneira, o PDHC almeja assegurar uma assessoria diferenciada do modelo clássico de Assistência Técnica e Extensão Rural (Ater), que durante anos foi marcado por práticas difusionistas que se preocupavam com a modernização, a renda e a produtividade do meio rural, desenvolvendo métodos e inovações tecnológicas excludentes ao agricultor familiar (FONSECA, 1985; CAPORAL, 2007; DIAS, 2008; CALLOU; TAUK SANTOS, 2013).

Essas mudanças, de acordo com o PDHC, necessitam de novos instrumentos que deverão ser baseados em metodologias participativas, que agreguem o agricultor e desenvolva suas potencialidades. Assim, segundo o PDHC, "as metodologias devem favorecer o aprendizado gradativo e a construção participativa/ coletiva dos conhecimentos. Nesses termos, os processos de aprendizado devem viabilizar a reflexão, a partir de uma vivência prática das famílias, no seu cotidiano, com as propostas em questão" (ARAÚJO; JALFIM; SIDERSKY, 2010, p. 27). Assim, para uma melhor compreensão das metodologias participativas, relacionamos alguns dos objetivos sugeridos no relatório do PDHC segundo Jalfim e Sidersky (2009):

i) Apoiar espaços interinstitucionais, democráticos para a implementação e controle de políticas públicas;

ii) fortalecer práticas organizacionais autônomas e solidárias;

iii) estimular e potencializar a participação direta de jovens;

iv) promover e apoiar ações para inclusão étnica, visando fortalecer a cidadania da população negra e indígena.

$\mathrm{O}$ PDHC, portanto, parece ir ao encontro do novo modelo de extensão rural que preconiza hoje a intervenção em comunidades rurais pautada nos princípios do diálogo de saberes e do desenvolvimento local (CAPORAL, 2007; LIMA; ROUX, 2008; CALLOU, 2013; CALLOU; TAUK SANTOS, 2013).

$\mathrm{Na}$ busca por uma compreensão a respeito de como as metodologias participativas estão sendo asseguradas no processo de reconfiguração da extensão rural, escolhemos o Projeto Dom Hélder Câmara como objeto desta pesquisa. Para isto, tomamos como referência a realidade do assentamento Moacir Lucena, no município de Apodi, RN. Reconhecido como de interesse social para fins de Reforma Agrária, em 24 de maio de 1998, portaria $\mathrm{n}^{\circ} 38$ de 27/05/1998, a partir de um processo de lutas e conquistas dos antigos agricultores da fazenda Boca da Mata, o assentamento é instituído como bem coletivo. O assentamento é composto por vinte famílias assentadas e oito agregadas, tendo uma área territorial totalizada em 549,91 hectares, apresentando uma área média por família, dividida por lotes de aproximadamente 19,6 ha e, ainda, de 50 ha de área desmatada e cerca de 59,7 ha 
de área coletiva (DANTAS et al., 2007). A escolha do assentamento Moacir Lucena deve-se ao fato de ele ter participado, de 2003 a 2013, de um trabalho de extensão orientado por técnicos da Cooperativa de Assessoria e Serviços Múltiplos ao Desenvolvimento Rural (Coopervida), órgão executor dos projetos do PDHC. Assim, a experiência do assentamento Moacir Lucena se mostrou como um campo fértil para se investigar sobre as implicações das metodologias participativas no campo do desenvolvimento local.

Nesse assentamento, o PDHC/ Coopervida conseguiu mobilizar os assentados do Moacir Lucena para participar de diversos projetos: caatinga manejada, horta, para ser explorada pelo grupo de jovens; apicultura; unidade de beneficiamento de polpas de frutas; e rebanho caprino para o grupo de mulheres. Entretanto os projetos pretendiam contribuir com os assentados no sentido de sensibilizá-los para a dinâmica produtiva e social do assentamento (JALFIM; SIDERSKY, 2009).

Nessecontexto, o PDHC/Coopervida tenta desenvolver metodologias para estimular a participação e superar a acomodação e omissão gerada pela extensão tradicional. Nessa discussão, merece relevância, segundo o PDHC, o aspecto social, que pode ser mediado através da assessoria técnica inovadora, que atenda a população, especialmente a mais pobre (JALFIM; SIDERSKY, 2009).

\section{PROCESSO DE INVESTIGAÇÃO}

Para atingir os objetivos deste artigo, consideramos os cinco canais estabelecidos por Demo (1993) que podem ser aplicados em determinado local: 1) organização da sociedade civil, compreendida como a capacidade histórica de a sociedade assumir formas conscientes e políticas de organização; 2) planejamento participativo, que diz respeito a uma estratégia concreta de enfrentamento dos problemas que afetam o grupo; 3) educação como formação à cidadania, relacionada ao processo formativo do sujeito do desenvolvimento, num contexto de direitos e deveres; 4) cultura como processo de identificação comunitária, isto é, a cultura como acesso a habilidades capazes de potencializar a criatividade do trabalho, lastro cultural próprio, que identifique num grupo social condição para se sentir; e 5) processo de conquista de direitos, quando leva à formação de ideologias comprometidas com processos de redução da desigualdade social e regional.

Optamos pelo método qualitativo para o desenvolvimento deste trabalho. Minayo (1996) destaca que esse tipo de abordagem permite uma análise mais profunda das relações, dos processos e dos fenômenos sociais.

Para o desenvolvimento inicial da pesquisa, acompanhamos uma reunião da associação dos posseiros do projeto de assentamento Moacir Lucena, na perspectiva de identificar as experiências de organização na comunidade, enfatizando as mudanças operadas no assentamento. Referente à revisão da literatura que trata da discussão sobre metodologias participativas, Lei de Ater e desenvolvimento local, foi acompanhada de um levantamento de documentos, relatórios e artigos científicos relacionados ao Projeto Dom Hélder Câmara/Coopervida. Foram essas fontes de informação, seguindo as observações metodológicas de Gil (2002), que permitiram uma análise preliminar quanto à heterogeneidade dos atores sociais envolvidos no processo participatório.

Escolhemos o estudo de caso como método investigativo, no sentido de que nos propomos a analisar um processo complexo, partindo de um contexto real (GIL, 2009). Esse método é ideal, como afirma Yin (2005), quando as questões que estão colocadas são do tipo "como" e "por que".

Foram realizadas entrevistas semiestruturadas, seguindo as instruções de 
Triviños (1987), com doze agricultores que fizeram parte dos cinco projetos produtivos do PDHC, no período de 2003 a 2013, abordando a participação das famílias nesses empreendimentos e a assessoria técnica recebida pelo PDHC/ Coopervida. Também foram analisadas a situação socioeconômica dos sujeitos e suas percepções em relação ao PDHC/ Coopervida Foram igualmente entrevistados três membros da diretoria da associação dos posseiros do assentamento Moacir Lucena, uma técnica da Coopervida que trabalhou no assentamento e dois membros da direção da unidade de gestão participativa (UGP) do PDHC.

Com os membros da diretoria da associação dos posseiros de Moacir Lucena, buscamos compreender as mudanças ocorridas na vida dos agricultores assentados em decorrência do acesso aos projetos financiados pelo PDHC e como estes contribuíram ou não para ampliar a participação dos agricultores na associação; com os técnicos da Coopervida e os dois membros da direção da UGP/PDHC, o interesse foi o de aprofundar as opiniões acerca das metodologias participativas do PDHC/Coopervida. Para preservar a identidade dos entrevistados, foram utilizados nomes fictícios nos depoimentos que aparecem nas análises.

\section{RESULTADOS E DISCUSSÕES}

\subsection{Organização da sociedade civil}

Como relatado no processo de investigação, os resultados da pesquisa contemplam a orientação metodológica adotada a partir dos cinco canais elencados por Demo (1993, p. 26) sobre a ideia de participação enquanto ação cidadã. Segundo o autor a organização da sociedade civil deve ser compreendida como a capacidade histórica da sociedade assumir formas conscientes e políticas de organização.

Ao fazer as entrevistas aos agricultores e agricultoras e vivenciar no mês de setembro de 2015 a rotina do assentamento Moacir durante sete dias, pôde-se constatar que a organização social teve sua origem na luta pela terra. Conquistar o chão para morar, plantar e viver motivou os agricultores à luta coletiva, criando um novo sistema social. Outro processo na dinâmica de organização local foi à construção das casas no assentamento, a sede da associação, o prédio para armazenamento das polpas de frutas e a sede poliesportiva, construídas em sistema de mutirão. Os agricultores lembram esse momento como algo emblemático na vida comunitária.

No que se refere ao incentivo da assessoria técnica por meio do PDHC/ Coopervida, quanto à organização comunitária, foi relatado pelos 12 agricultores e agricultoras entrevistados como um período importante para a dinâmica da comunidade, sendo que todas as atividades dos projetos estavam em volta das discussões, reuniões e encontros do Sindicato dos Trabalhadores e Trabalhadoras Rurais (STTR), fórum dos agricultores familiares de Apodi e Cooperativa dos agricultores familiares da cidade do Apodi (Cooafap) e a própria associação comunitária.

Ainda com base na participação dos agricultores nos espaços coletivos, a assessora técnica da Coopervida caracteriza esses momentos como um bem inatingível que possibilitou empoderá-los para mobilização, organização e comercialização dos próprios produtos, dando visibilidade aos atores mais excluídos, que eram as mulheres e os jovens da comunidade. A técnica ainda reforça como aspecto positivo o uso das metodologias participativas, como ferramenta essencial desse processo, para ela o simples fato de ouvir, parar e deixar o outro falar já é um fator positivo dentro dos espaços coletivos, principalmente se tratando do meio rural em que o agricultor sempre foi desvalorizado, onde por um longo período nos foi ensinado que o saber do extensionista estava acima do saber popular. Enfatiza a técnica "as metodologias participativas 
fizeram grande diferença, estimular os agricultores a falarem, opinarem sobre as decisões coletivas só foi possível pelo uso de ferramentas participativas".

Nesse sentido, a assessoria técnica, ao adotar metodologias participativas, cria um instrumento viabilizador com capacidade de definir e gerar um processo endógeno de mudança, que leva em conta o econômico e a melhoria da qualidade de vida da comunidade, por meio da organização e participação dos agricultores nos processos de decisão. Esses aspectos vão ao encontro do conceito de desenvolvimento local, compreendido como a melhoria da qualidade de vida da população, a partir de esforços endógenos locais (BUARQUE, 1999).

Além das discussões para decidir a aplicação dos recursos destinados aos espaços coletivos, as reuniões e os encontros promovidos pela assessoria técnica constituíram-se em laços importantes para a auto-organização. Conforme podemos perceber no depoimento do agricultor Zumbi "tinha muitas reuniões pra tudo, era tudo decidido no coletivo, nas reuniões eram levadas as pautas pra nós agricultores dizer o que era melhor pra gente". Como podemos observar, a presença dos agricultores nos projetos financiados pelo PDHC/Coopervida (manejo da caatinga, caprinocultura, polpas de frutas, apicultura e hortas) foi fundamental para manter o trabalho coletivo, com base nas metodologias participativas, através do diálogo, escuta e aprendizado dos envolvidos.

Fato é que, a partir do momento em que os técnicos da Coopervida deram por concluída a assessoria técnica em Moacir Lucena, em 2013, os agricultores passaram, pouco a pouco, por dificuldades no que se refere à organização comunitária. Todos os 12 agricultores entrevistados foram enfáticos, ao afirmar essas dificuldades, entre elas, ausência dos moradores nas reuniões da associação, ausência de representantes do assentamento nos encontros municipais referentes às pautas da agricultura familiar, descontinuidade de grande parcela dos projetos financiados pelo PDHC, como o projeto de caprinocultura, hortas, apicultura e grande parte das polpas de frutas. Dos 12 agricultores entrevistados, apenas dois ainda dão continuidade ao projeto polpas de frutas, mesmo que de forma individual vendendo de porta em porta na cidade de Apodi, RN. Em relação ao projeto manejo da caatinga, conforme verificado durante a vivência no assentamento, os agricultores têm buscado a diversificação da biodiversidade no lote como forma alternativa de manutenção do bioma Caatinga e, como afirma o agricultor Burnier, também como obtenção de renda, uma vez que o agricultor vende a madeira extraída no lote de forma sustentável, respeitando todas as orientações passadas pelo engenheiro agronômico durante a formação do projeto.

Essas falas sugerem o quanto ainda os agricultores estão dependentes e à espera da assessoria técnica para dar continuidade aos projetos produtivos desenvolvidos pelo PDHC/Coopervida em Moacir Lucena. Com isto, podemos inferir que, mesmo com um acompanhamento técnico ininterrupto de dez anos, por meio de metodologias participativas, os agricultores encontram-se, ainda, numa situação aquém daquela esperada pelo PDHC/Coopervida.

Entretanto há outras variáveis que não foram contempladas neste trabalho, mas que, de alguma maneira, podem ter comprometido o desenvolvimento das atividades produtivas em Moacir Lucena, após a saída dos técnicos da comunidade. Podemos citar, por exemplo, o longo período de seca, a fiscalização das polpas de frutas por parte da Anvisa, a insuficiência de água para manter o projeto de hortas, bem como fatores ligados ao contexto histórico de subalternidade ao qual estão submetidos os agricultores, como assinala Carvalho (1994). 
Seja como for, nesses 10 anos de assessoria técnica, as entrevistas revelaram que o trabalho do PDHC/Coopervida foi fundamental na organização comunitária. Este processo, entretanto, não foi isento de conflitos, fundamentais, como pontua Oliveira (2001), nas discussões sobre direitos sociais no desenvolvimento local, ampliando, por seu turno, as capacidades de as pessoas decidirem o tipo de vida que desejam ter.

\subsection{Planejamento Participativo}

No planejamento dos projetos financiados pelo PDHC/Coopervida, foram realizados, segundo Jalfim e Sidersky (2009), reuniões, assembleias e encontros, objetivando, principalmente, uma proposta alternativa, comprometida com a redistribuição do poder, avessa ao assistencialismo. Com base em Demo (1993), resumidamente, pode-se apontar que o planejamento participativo diz respeito a uma estratégia concreta de enfrentamento dos problemas que afetam o grupo. Assim, no que se refere ao papel das metodologias participativas na definição, elaboração e execução dos projetos a serem financiados pelo PDHC e executados pela Coopervida, constatou-se, por meio dos agricultores entrevistados, que as metodologias se pautaram na escuta, diálogo, formação e comprometimento com a realidade social de Moacir Lucena. Podemos perceber, a partir da fala do agricultor Zé Maria, "tudo aqui era decidido nas reuniões, seja na associação ou em cada projeto, mas sempre escutava o povo na hora de decidir"; outro relato é da agricultora Adelaide "Os técnicos diziam: a opinião é de vocês, eu tô aqui só para cumprir o que vocês determinam e ver que é possível, estamos aqui pra ajudar".

Esses depoimentos revelam, por outro lado, o olhar atento da assessoria técnica quanto à participação dos agricultores na livre escolha dos projetos, por meio de atividades, nas quais o diálogo entre técnicos e agricultores assume papel preponderante. Assim, esclarecem os dois membros da direção da UGP/PDHC: "sempre se planejou com as famílias, com a assessoria técnica, identificando seus problemas, seus potenciais, criando um plano local, o plano do assentamento." Nessa situação, os agricultores assumem um papel de beneficiários ativos na política pública de extensão rural. Esse aspecto propicia aos agricultores o desenvolvimento de habilidades para negociar com os técnicos os projetos a serem implementados no assentamento. Vione (2002) caracteriza as metodologias participativas como essenciais para provocar impactos positivos sobre a organização e participação comunitária.

Em relação ao planejamento de cada projeto, foi adotada pelo PDHC uma metodologia que possibilitasse aos agricultores e agricultoras realizar uma avaliação dos projetos produtivos, dessa forma, havia uma menor interferência do técnico que atuava em Moacir Lucena no encaminhamento e momento avaliativo de cada projeto. Assim, eram destinados técnicos de outras áreas para fazer o planejamento, junto com os agricultores. O planejamento, porém, não perdia de vista as peculiaridades dos agricultores e, consequentemente, as implicações sociais, econômicas e participativas, como enfatiza ainda a técnica da Coopervida "planejar antes de tudo era dar voz aos principais envolvidos no processo, era deixar o agricultor e agricultora falar, opinar sobre o que era melhor na vida deles". Esta era, talvez, a razão pela qual o PDHC evitava, no planejamento, a interferência direta da equipe técnica, como uma estratégia metodológica para estimular os agricultores a participar, adotar e internalizar a importância do planejamento participativo na vida comunitária.

Os agricultores entrevistados reconhecem a importância dessa metodologia para o empoderamento da comunidade. É o que pode ser observado no relato de dois 
agricultores, Romero ao enfatizar "hoje eu consigo entender por que eles queriam que nós falássemos. A importância de dizer o que pensa. Quando você não fica calado, o outro começa a lhe respeitar, porque sabe que você entende o que está sendo falado" e Ezequiel ao mencionar a importância desse espaço para sua vida pessoal "Os planejamentos mudaram minha vida; de tanto eles pedirem pra falar, hoje eu falo até demais (risos)". O efeito desse processo é a capacidade de gerar processos de desenvolvimento autossustentável, a partir do planejamento participativo, fundamentais na organização e no desenvolvimento de projetos comunitários, como nos lembra Gohn (2004).

Percebe-se que, de modo geral, os agricultores familiares entrevistados atribuem o ato de falar em público à assessoria do PDHC/Coopervida e a justificam a partir de alguns fatores: a escuta por meio da assessoria, o incentivo a expor suas ideias e, ainda, a valorização do saber que permite o conhecimento do agricultor ser partilhado. Desse modo, infere-se que as estratégias metodológicas utilizadas pelo PDHC/Coopervida nos planejamentos participativos em Moacir Lucena foram fundamentais para promover a participação e a autoestima dos agricultores e agricultoras envolvidos nos projetos produtivos.

\subsection{Educação como formação à cidadania}

Neste momento será analisada, a partir do pensamento de Demo (1993), a educação como formação à cidadania, relacionada ao processo formativo do sujeito do desenvolvimento, num contexto de direitos e deveres.

O cenário da luta contra direitos negados ao campo e o enfrentamento da exclusão social conduziram os agricultores de Moacir Lucena à implementação de uma escola na comunidade. A escola funciona na sede da associação, numa sala improvisada. O poder público municipal disponibilizou uma professora para atender todas as crianças do ensino fundamental I, por meio da formação multissérie. Para cursar as séries seguintes, os estudantes se deslocam até o distrito de Soledade para dar início ao ensino fundamental II, enquanto o ensino médio é ministrado na sede do município de Apodi. Os alunos utilizam o transporte escolar cedido pela Prefeitura.

Como se pode observar, a ausência de políticas públicas educacionais no meio rural ainda é um desafio em contextos de exclusão social. Essa situação é ainda mais grave, como se referem Arroyo, Caldart e Molina (2011), quando se observa a ineficiência do ensino nessas localidades.

Nesse cenário, a equipe técnica da Coopervida buscou desenvolver uma educação popular dentro dos projetos produtivos, por meio das metodologias participativas, entre elas a escuta e o espaço de fala dos agricultores. A técnica entrevistada reconhece que as metodologias participativas foram ferramentas importantes no apoio a cada projeto, em que os sujeitos eram envolvidos na construção do saber. Diz ela "a educação deve ser construída a partir da integração do saber técnico e popular do agricultor, tudo que vai ser feito em determinado projeto deve passar pelos beneficiados!". Indo ao encontro da fala da técnica, os dois membros da direção da UGP/PDHC ressaltam "é a partir das metodologias participativas que o saber do agricultor deve ser incorporado às novas tecnologias sociais e seu saber deve ser totalmente estimulado".

Essa relação de confiança entre técnico e agricultor, a partir das metodologias participativas inseridas na assessoria, pode ser afirmada no relato da agricultora Cleusa ao enfatizar "vinha muita gente de fora falar, conversar, explicar o que era agroecologia, como reaproveitar a água para plantio das hortas. E a gente ia para intercâmbios fora, conhecer outros 
agricultores, quando foi pra ter o projeto das cabras, hortas, foram ver outras experiências". Outra fala importante é do agricultor Chico, "nunca se contrapôs (os técnicos) ao conhecimento do agricultor, deixava a gente falar, na verdade eles pediam pra dizer o que pensava o que nós queríamos". A essência da confiança se baseia nas dinâmicas socioeconômicas agrícolas e não agrícolas que passam a ser centradas nos atores sociais locais.

Além das discussões acerca de diferentes temas relacionados às atividades agrícolas, as reuniões, encontros e cursos se constituíram também em espaços de formação em diversos outros assuntos, entre eles gênero, juventude rural, associativismo, agrotóxicos, conduzidos pela assessoria técnica ou convidados. As formações normalmente aconteciam no próprio assentamento, como forma de estimular, facilitar e garantir a participação dos agricultores, principalmente das agricultoras, em virtude de seus afazeres domésticos. Aspecto ressaltado por Farah (2004), particularmente no que se refere à abertura de espaços para que as mulheres possam contribuir cada vez mais nos processos decisórios, valorizando suas vidas, por elas mesmas e pelas pessoas que as cercam.

O uso de elementos presentes no cotidiano do agricultor era fundamental para a participação nas reuniões dos projetos. Assim, eram usados objetos conhecidos pelos assentados. Diz a técnica: "para trabalhar, explicar o que é agroecologia, uma vez eu fiz assim, pedi para cada um trazer de casa algo que eles achavam que representava a agroecologia. A metodologia popular nos ajudou muito, eles iam entendendo a mensagem a partir dos símbolos usados". Os dois membros da direção da UGP/PDHC revelaram que os técnicos eram orientados a construir um projeto, a partir do encontro de conhecimentos, sendo necessária certa horizontalidade do saber. Como salienta Caldart (2000), trata-se de uma pedagogia que vai além da escola, que é organizada nos movimentos sociais, na prática social. Nesse sentido, diz que as metodologias têm que levar a construção participativa ao encontro de saberes para um novo patamar de conhecimentos, capaz de criar e dar condições para mais qualidade de vida.

Todas essas abordagens mostram na ação da assessoria técnica um significado eminentemente educativo, na medida em que as atividades decorrentes dos projetos eram desconhecidas dos agricultores, a exemplo do manejo da caatinga, polpas e apicultura. Nesse sentido, novas estratégias metodológicas de educação popular foram adotadas, tendo como pressupostos a valorização do saber do outro, o diálogo e a escuta, por meio de cursos, encontros, intercâmbios e palestras em diversos locais, oferecidos aos agricultores. Assim, enfatiza o agricultor Romero, “os técnicos despertaram potenciais que estavam adormecidos, faltava uma luz para nos orientar. Os projetos sempre se basearam nas propostas dos agricultores, nunca foi contrário ao que diziam".

Por outro lado, a técnica entrevistada reconhece que trabalhar com metodologias participativas é algo complexo, principalmente com agricultores semianalfabetos e que vivem historicamente num contexto social de submissão. Para mudar esse sistema, esclarece a técnica, requer tempo e acompanhamento permanente. Diz ela: "nós éramos sensíveis a isso, nós tentávamos desconstruir no Dom Hélder, com muita dificuldade porque os trabalhadores não eram alfabetizados, muitas vezes a questão da participação era difícil, eles tinham receio de tá falando". Essa observação chama a atenção sobre a importância da educação formal e informal para promoção da mobilização social no meio rural. Aspecto também corroborado pelos dois membros da direção da UGP/ PDHC.

As metodologias participativas, ao privilegiar o diálogo e a valorização do 
outro como sujeito de mudança, foram avaliadas pela técnica da Coopervida como ferramentas importantes nesse processo; assim diz, "você escutar as pessoas falarem é a coisa mais importante do mundo. Nós da Coopervida combatíamos isso de chegar a um lugar achando que sei de tudo, é preciso ouvir o que o agricultor tem a dizer". Todos esses aspectos possibilitam reafirmar a necessidade das metodologias participativas na extensão rural, devendo seus assessores atuar como animadores, mediadores de um processo que deve ser conduzido pelos próprios agricultores.

Percebe-se que os agricultores e agricultoras entrevistados, com todo seu conhecimento pragmático sobre a terra e suas formas de produção e reprodução, reconhecem a importância dos projetos financiados pelo PDHC e executados pela Coopervida, além de enfatizarem nas entrevistas a qualidade do acompanhamento durante os dez anos de vivência no assentamento. Portanto as metodologias participativas devem ser vistas como um fator positivo, pois, ao possibilitar o contato direto dos assessores com os agricultores, permite conhecer seus desejos, criar vínculos e respeito que vão além de uma simples assessoria. Ou seja, possibilitam confiança na coletividade e credibilidade em si próprio.

\subsection{Cultura como processo de identificação comunitária}

A perspectiva de cultura abordada por Demo (1993), enquanto processo de identificação comunitária, a partir da ativação das potencialidades e criatividades locais, foi observada nos projetos desenvolvidos pelo PDHC/Coopervida em Moacir Lucena. As metodologias participativas utilizadas pelos técnicos da Coopervida possibilitaram construir um alicerce para a organização comunitária, ao considerar elementos culturais endógenos do assentamento, a exemplo dos hábitos alimentares, as formas fitoterápicas para a cura de doenças, as técnicas de cultivo e colheita agrícola e, sobretudo, as formas de solidariedade e vizinhança. O depoimento da agricultora Margarida revela o quanto a equipe técnica foi importante para a identificação comunitária "acho que foi o início de tudo aqui. A gente sempre foi unido mesmo antes dos técnicos virem pra cá, mas nunca tínhamos nos organizado de fato, só na luta da terra, depois todos paramos, quando os projetos chegaram, aí sim, foi o tempo de aprendermos muitas coisas".

Em relação aos projetos do manejo da caatinga, caprinocultura, polpas de frutas, apicultura e hortas são vistos pelos entrevistados como o grande diferencial na vida comunitária. É a partir deles que os agricultores, de fato, vão iniciar a sua identificação como comunidade. Para a agricultora Dorothy, estar envolvida nos projetos proporcionou aprendizado e confiança no coletivo, assim menciona ela, "participar dos projetos mudou tudo, eu digo por mim e por todos que entraram. Ninguém ficou igual e nem a comunidade, porque tudo era feito junto, não tinha individualismo. A importância de estarmos unidos foi orientada nas reuniões. Os costumes da comunidade sempre foram respeitados pelos técnicos. Eu digo por mim, sempre acreditei nos remédios caseiros, nas rezas e eles nunca falaram nada".

Essas características são fortalecidas pela presença da assessoria técnica, por meio das metodologias participativas utilizadas, que primavam pelas decisões coletivas e respeito à cultura local. Diz a técnica da Coopervida: "a Coopervida e o Dom Helder sempre estavam atentos a projetos que respeitassem a identidade de camponês. Havia essa preocupação em mostrar que era possível ser agricultor e viver bem". Identificar-se como agricultor ou agricultora fortalece os laços existentes nos projetos comunitários, como nos lembra o agricultor Josimo, "Eu sempre tive orgulho de dizer que sou agricultor, 
nunca tive vergonha e olhe que é uma vida muito difícil". No entanto, devido à vida difícil, a ausência de políticas públicas e o imaginário ainda do "jeca tatu" para os que residem no campo, muitos jovens têm certa dificuldade de identificar-se com seu espaço. Seguindo essa linha de pensamento, a jovem agricultora Dorothy, nos lembra do quanto o PDHC/Coopervida foram importantes para a construção de sua identidade como agricultor, assim diz ela "quando eu era mais nova, eu tinha vergonha de dizer que era agricultora. Lá em Apodi, quando eu estudava, o povo mangava e eu ficava encabulada. Depois que os técnicos vieram e disseram a importância do agricultor pra sociedade, hoje eu entendo que é importante ser agricultora".

Nesses termos, podemos inferir que o trabalho de assessoria técnica, por meio das metodologias participativas utilizadas, possibilitou que os agricultores reafirmassem sua identidade cultural, muitas vezes represada pela educação formal. Uma pedagogia participante, libertadora e inclusiva, como nos lembra Freire (2008), vai além da escola, pois pode ser organizada nos movimentos sociais e na prática social, a partir dos traços culturais existentes em cada comunidade.

\subsection{Processo de conquista de direitos}

Compreender como se deu o processo de conquista de direitos no assentamento Moacir Lucena constituiu-se uma tarefa imprescindível para a análise da tomada de consciência dos agricultores, diante das injustiças e manipulação do poder do Estado. Na perspectiva de Demo (1993), o processo de conquista de direitos deve partir da formação de ideologias comprometidas com processos de redução da desigualdade social e regional. Nesse sentido, a participação dos agricultores nas reuniões, encontros e intercâmbios promovidos por diversas entidades possibilitou fornecer elementos para a promoção dos projetos coletivos e pessoais que puderam despertar o olhar crítico diante da realidade.

Nesses espaços de formação e mobilização para a cidadania que a conquista de direitos deve emergir, representando a capacidade de organização efetiva e o enfrentamento diante das injustiças, como nos lembra Jacobi (2003). Para os dois membros da direção da UGP/PDHC, esses momentos formativos tiveram significado fundamental quando mencionam que "esses espaços tinham como função principal o despertar da consciência dos agricultores, para animá-los às lutas sociais".

No tocante ao direito à terra, é possível perceber nas falas dos agricultores de Moacir Lucena que o valor dado a esse bem vai além do econômico, pois perpassado pelo aspecto sentimental e cidadão. A fala a seguir é representativa desse aspecto, quando Zé Maria diz, "foi o dia mais feliz quando a terra passou a ser nossa e também porque agora nós tínhamos nosso direito de plantar só pra nós".

Outro direito não menos importante para os agricultores foi a questão da moradia. A luta em fazer a planta e construção da casa, de acordo com o desejo dos assentados, possibilitou um apego muito maior a esse bem. Nesse contexto, o PDHC/ Coopervida fortaleceu, por meio das metodologias participativas, os vínculos de solidariedade e confiança já existentes em Moacir Lucena. As discussões nas reuniões dos projetos giravam em torno dos problemas comunitários, direitos sociais, participação do assentamento nos espaços de interesse dos agricultores, entre outras.

Referente ao quadro de miséria vivido pelos agricultores, antes do financiamento dos projetos do PDHC, os técnicos trabalharam temas, como o direito à alimentação. Segundo a técnica da Coopervida, trabalhar com os agricultores a melhoria da qualidade de vida era, antes de tudo, romper com o sistema opressor, a partir do acesso ao alimento, 
seja através da galinha, do feijão ou hortas. No tocante ao direito à igualdade de oportunidades entre homens e mulheres, constatou-se que a assessoria técnica fez um trabalho dedicado à discussão de gênero, com a criação de um grupo de mulheres, com espaço de formação e socialização. Assim se refere a agricultora Adelaide: "nós mulheres sempre fomos muito discriminadas, não podíamos falar nas reuniões da comunidade (associação). Só quem tinha direito eram os homens. Depois isso foi mudando, a técnica na minha vida foi uma benção, minha vida melhorou muito depois das palestras dela. $\mathrm{Eu}$ fui entendendo que eu posso fazer o que quiser e que também tenho direito de ir pra onde quero".

No entanto, após o encerramento das atividades do PDHC, no assentamento, o grupo de mulheres deixou de se reunir. Todavia, mesmo com um grupo não formalizado, os processos de decisão na comunidade têm a presença da mulher, mesmo que seja, ainda, em número reduzido, como nos informa a agricultora Margarida: "se tiver qualquer coisa aqui, eu vou pra saber o que vai ser feito na comunidade. Muitas mulheres desanimaram, mas ainda tem ainda umas resistindo e eu sou uma delas".

Assim, podemos inferir que o trabalho realizado pelo PDHC/Coopervida contribuiu para o rompimento das manipulações impostas pelo contexto social, embora a pesquisa tenha evidenciado certos limites participativos após o encerramento da assessoria técnica em Moacir Lucena. Como lembra Demo (1993, p. 18), "não existe [participação] suficiente e nem acabada. Participação que se imagina completa, nisso mesmo começa a regredir".

\section{CONCLUSÃO}

As análises apresentadas ao longo deste trabalho revelaram que as metodologias participativas, utilizadas pelo
PDHC/Coopervida - o estímulo para que homens, mulheres e jovens do assentamento se coloquem nas reuniões para participação e mobilização comunitária, o desenvolvimento da escuta por parte dos técnicos em relação às demandas dos agricultores, as reuniões de planejamento para decisão coletiva de ações, os cursos realizados à luz das necessidades e do respeito à cultura local, os contatos dos assentados com outras comunidades, o enfrentamento e a resolução de conflitos, a educação informal pautada na troca de saberes -, colaboraram para que as famílias de Moacir Lucena experimentassem formas diferenciadas de assistência técnica e extensão rural, na perspectiva do desenvolvimento local.

O trabalho conjunto desenvolvido entre o PDHC/Coopervida e os agricultores de Moacir Lucena, durante os 10 anos de atividades, revelou que o acesso às metodologias participativas contribuiu para a participação e o empoderamento dos agricultores e agricultoras no assentamento, refletidos, principalmente, no nível de organização comunitária alcançado, que possibilitou construir, na comunidade, os projetos produtivos financiados pelo PDHC.

Entretanto, com o encerramento das atividades de extensão e de assistência técnica do PDHC/Coopervida em Moacir Lucena, o que se observou foi um desânimo dos agricultores para tocar sozinhos os projetos produtivos implantados na comunidade. Mesmo que tenha sido longo o tempo de assessoria técnica do PDHC/ Coopervida no assentamento, se comparado a outros trabalhos de Extensão Rural desenvolvidos em comunidades rurais, houve vários depoimentos de assentados, alegando a necessidade de continuidade da assistência técnica especializada para os projetos econômicos produtivos no assentamento.

Em decorrência disso, um processo gradual de desmobilização comunitária e enfraquecimento econômico dos 
agricultores foi percebido por meio das entrevistas. Aspectos agravaram-se em virtude do longo período de estiagem na região, das exigências da Anvisa na produção de polpas de frutas, além da falta de políticas públicas, por parte do governo local, para apoiar o assentamento. Uma explicação de caráter mais geral dessa situação pode estar ligada à dependência política e social a que a população do campo, em particular a do semiárido, ficou submetida historicamente. No passado, a Extensão Rural reforçou esse tipo de dependência, por meio dos projetos verticais de desenvolvimento rural.

Por fim, podemos inferir que as metodologias participativas utilizadas pela Extensão Rural e assistência técnica do PDHC contribuíram na perspectiva do desenvolvimento local de Moacir Lucena. Por meio dessas metodologias, as atividades do PDHC/Coopervida foram capazes de considerar as vocações e potencialidades econômicas locais, gerir coletivamente os processos decisórios na comunidade, estimular o associativismo e a autonomia dos agricultores. Esses aspectos refletiram, apesar do encerramento das atividades do PDHC/Coopervida, em Moacir Lucena, uma melhoria da qualidade de vida dos sujeitos envolvidos, além de despertá-los para a importância do trabalho coletivo, no enfrentamento dos problemas econômicos e sociais do campo.

\section{REFERÊNCIAS}

ARAÚJO, E. R; JALFIM, F. T.; SIDERSKY, P. R. A estratégia de assessoria do projeto Dom Helder Camara. 2. ed. Recife: Projeto Dom Helder Câmara, 2010.

ARROYO, M.; CALDART, R. S.; MOLINA, M. (Org.). Por uma educação do campo. 5. ed. Rio de Janeiro: Vozes, 2011. p. 30-98.

BUARQUE, S. C. Metodologia de planejamento do desenvolvimento sustentável, Brasília: IICA, 1999.

CALDART, R. S. Pedagogia do movimento sem-terra. Rio de Janeiro: Vozes, 2000. p. 45-102.
CALLOU, A. B. F. Extensão Rural: polissemia e resistência. In: CALLOU, A. B. F.; TAUK SANTOS, M. S. (Org.). Extensão rural - extensão pesqueira: estratégias de ensino e pesquisa. 1. ed. Recife: FASA, 2013. p. 19-48.

CALLOU, A. B. F; TAUK SANTOS, M. S. desafios da comunicação rural em tempo de desenvolvimento local. In: CALLOU, A. B. F.; TAUK SANTOS, M. S. (Org.). Extensão rural - extensão pesqueira: estratégias de ensino e pesquisa. 1. ed. Recife: FASA, 2013. p. 477-482.

CAPORAL, F. R. Extensão rural e agroecologia: temas sobre um novo desenvolvimento rural, necessário e possível. Brasília: Ministério do Desenvolvimento Agrário, 2007.

CARVALHO,H. M. de. Participação e cidadania. Projeto Aridas: uma estratégia de desenvolvimento sustentável para o Nordeste. Brasília: Secretaria de Planejamento, Orçamento e Coordenação da Presidência da República, 1994.

DANTAS, L. B.; FILHO, J. L.; LIRA, J. F. B.; MARACAJÁ, P. B.; FILHO, E. T. A agroecologia nos assentamentos de: Moaci Lucena, Sítio do Góis e Vila Nova em Apodi - RN. Revista GVAA, Mossoró, v. 1, n. 1, p. 1-12, jan./mar. 2007.

DEMO, P. Participação é conquista. Fortaleza: EUFC, 1993.

DIAS, M. M. Políticas públicas de extensão rural e inovações conceituais: limites e potencialidades. Perspectivas em Políticas Públicas, Belo Horizonte, v. 1, n. 1, jun./ dez. 2008.

FARAH, M. F. S. Gênero e políticas públicas. Revista Estudos Feministas, Florianópolis, v. 12, n. 1, p. 47-72, jan./abr. 2004.

FREIRE, Paulo. Pedagogia do oprimido. 47. ed. Rio de Janeiro: Paz e Terra, 2008.

FONSECA, M. T. L. da. A extensão rural no Brasil, um projeto educativo para o capital. São Paulo: Loyola, 1985. 92p. (Coleção educação popular, n. 3).

GIL, A. C. Métodos e técnicas de pesquisa social. 6. ed. São Paulo: Atlas, 2009.

Como elaborar projetos de pesquisa. 4. ed. São Paulo: Atlas, 2002.

GOHN, M. da G. Empoderamento e participação da comunidade em políticas sociais. 
Saúde e Sociedade, São Paulo, v. 13, n. 2, p. 2031, maio/ago. 2004.

JACOBI, P. Pobreza e forma de ação coletiva. In: CAMAROTI, I.; SPINK, P. (Org.). Estratégias locais para a redução da pobreza: construindo a cidadania. Programa de Gestão Pública e Cidadania - Fundação Getúlio Vargas. São Paulo: EAESP, 2003. p. 23-46.

JALFIM, F; SIDERSKY, P. A estratégia de assessoria técnica do projeto Dom Helder Camara. Recife: Projeto Dom Helder Câmara, 2009.

LIMA, I. S.; ROUX, B. As estratégias de comunicação nas políticas públicas de assistência e extensão rural para a agricultura familiar no Brasil. In: CIMADEVILLA, G. Comunicación, tecnologia y desarrollo. Rio Cuarto: Universi- dad Nacional de Rio Cuarto, 2008. p. 91-112. v. 1.

MINAYO, M. C. de S. O desafio do conhecimento: pesquisa qualitativa em saúde. 4. ed. São Paulo, 1996.

TRIVIÑOS, A. N. S. Introdução à pesquisa em ciências sociais: a pesquisa qualitativa em educação. 1. ed. São Paulo: Atlas, 1987.

VIONE, G. F. Metodologias participativas na construção de planos de desenvolvimento local. 2002. 47 f. Trabalho de Conclusão de Curso (Especialização em Desenvolvimento, Agricultura e Sociedade) - Universidade Federal Rural do Rio de Janeiro, Seropédica, RJ, 2002. YIN, R. K. Estudo de caso: planejamento e métodos. 3. ed. Porto Alegre: Bookman, 2005.

\section{Sobre os autores:}

Josiani Alves de Morais: Bacharela em Gestão Ambiental pela Universidade Estadual do Rio Grande do Norte. Mestre em Extensão Rural e Desenvolvimento Local na Universidade Federal Rural de Pernambuco (UFRPE). E-mail: Josi.morais@yahoo.com.br

Angelo Brás Fernandes Callou: Graduação em Engenharia de Pesca pela Universidade Federal Rural de Pernambuco, mestrado em Extensão Rural pela Universidade Federal de Santa Maria e doutorado em Ciências da Comunicação pela Universidade de São Paulo. Professor titular da Universidade Federal Rural de Pernambuco (UFRPE). E-mail: abcallou@gmail.com 
